\title{
Contact, communication and compassion as stairways to peace: A holistic sociological perspective
}

\author{
Shulamit S. Gubkin \\ Department of Sociology, Kinneret College at the Jordan Valley, Upper Galilee, 15132, Israel.
}

Accepted 10 April, 2013

\begin{abstract}
This paper describes the attitudes of academic Israeli students of Jewish and Arab descent after having participated in diverse processes to promote cross-cultural empathic communication within special workshops and in regular academic courses. Grounded in a holistic planetary consciousness perspective, these experiences suggest that empathy, caring, loving and compassion, taken together as a synergistic gestalt of pro-social behavior, can indeed be trained. It is further suggested that such training is urgently needed to sustain life as we know it, and that it appears conducive to optimism, builds hope towards eventual peace and contributes to more effective and meaningful participation in the world for all those involved. Theoretically, this paper suggests an emerging sociological paradigm shift that embraces the subjective experience together with the structural analyses of planetary circumstances, the promotion of necessary institutional change and a committed activism towards a sustainable society. Such framework addresses and embraces the four dimensions suggested in Burawoy's 2004 ASA Presidential Address to the American Sociological Association for public and holistic sociology, and it resonates with Sorokin's Integralist perspective.
\end{abstract}

Key words: Holistic sociology, planetary consciousness, communication, empathy, compassion, peace.

\section{THE CHALLENGE: ISRAEL'S MULTICULTURAL SEGREGATION}

Israel is a country with a high degree of cultural diversity, deeply divided and segregated along multiple sociocultural dimensions. The most significant among these divisions is between Jews and Arabs, reflecting national, ethnic and religious affiliations, rooted in the land dispute existing since the time of the formation of the State of Israel. Institutionally anchored in the basic definition of Israel as an ethnic (Jewish) democracy, or a second-rate ethnic democracy (Smooha, 2009), there is a marked "invisible" barrier among these population groups in the State and society, in practically all spheres of life. Most Arab citizens of Israel are Muslim, and there is a significant Arab Druze and Arab Christian minority from various denominations, among other religious communities, with very different characteristics not only relating to religion, but also in relation to attitudes 
regarding the State, military service (required by law or optional for different population groups), to Palestine and Palestinian identity, and a post-modern secular urban life style.

Within the Jewish population, a major gap exists along religious-secular lines as well as along political and ideological ones, and between native-born Israelis and immigrants. These multiple divisions and power asymmetries (Dudouet, 2005) are marked by a high degree of segregation, even when the people involved may be (and usually are) living in close, yet selfenclosed, physical proximity.

This complexity is manifested in a diverse array of selfreferenced identities (such as "Israeli Arab","IsraeliPalestinian", "Israeli-Palestinian Arab", "Palestinian with Israeli identity card") and it definitely restricts the appropriate reference to the group as a whole. This paper refers to them as "Arabs" and "Jews", reflecting the grassroots and public discourse. Yet this is done with considerable unease, as those categories are generalizations that ossify the stereotypically simplified social contexts, thus causing further self-regeneration.

\section{HOLISTIC SOCIOLOGICAL FOUNDATIONS: A GLOBAL MOVEMENT TOWARDS PLANETARY CONSCIOUSNESS -- CONNECTING INNER AND OUTER PERSPECTIVES}

The theoretical foundations of the work described in this paper are grounded in a holistic sociology paradigm evolved from my (U.C. Berkeley) PhD thesis on "A movement towards planetary consciousness: The case of the San Francisco Bay area" (Gubkin, 1995).

The research on this emerging planetary consciousness started in the 1980's, prompted by the global sustainability challenge we are confronted with at the dawn of the $21^{\text {st }}$ century, and what emerged as an innovative, creative, attempt to respond to it at the grassroots level. Today we seem to be at an even greater crossroads, confronting a choice between evolving towards a conscious, mature species with concern for an ongoing, lasting legacy and a responsibility for the future or becoming an irrational, self-destructive species concerned only with spontaneous, arbitrary creativity and indiscriminate indulgence that bears no sense of livable future at all. With our contemporary technology, we have assumed the awesome responsibility of stewardship of the Earth. It is a time when the future of all life on Earth is in human hands, and that in itself implies a need, greater than at any other time in human history, for a deeper awareness and a deeper sense of both self and interconnectedness.

This predicament is, unfortunately, not surprising, nor is its observation new. The prominent sociologist Pitirim Sorokin, for example, in his conclusion of The Crisis of Our Age, in 1941, forcefully stated that "Western society, like some before it, has gone so far in the dominance of 'sensate' values that it must almost inevitably swing back, probably to a better, integral, balance of inner-directed and outer-directed values" (Harman, 1988). In Sorokin's tripartite typology, a sensate society is deeply entrenched in a materialistic perspective, which socializes into the collective perception of individualism and "rational choice". It organizes reality through an empirical principle of truth that is revealed through the senses (Jeffries, 1999). Human needs are here considered to be physical and satisfied by developing the environment. Indeed, as Johnston (1999, p. 29) summarizes, "sensate knowledge gives science, technology and physical comfort, but tells little of the spirit". As the twentieth century's events of collective self-destruction intensified, Sorokin more poignantly warned not only the academic community but wide public audiences as well about the dangers and vicissitudes of what has now inexorably evolved into a decaying stage of sensate culture.

What is obvious at this historical juncture is the global/planetary nature of our contemporary challenges and their possible solutions. That is, the personal, social, and natural worlds are increasingly appearing as deeply interconnected. Indeed, such global interdependence is becoming obvious to people from all walks of life, and not exclusively, or essentially, to experts, as was true in the past. Many succumb to fear and to a sense of helplessness, denial or despair (Lasch,1984); others regress to "tribalism", religious fundamentalist and ethnocentric-nationalistic ideologies forcefully resisting the principle of "unity within diversity", essential to the web of life and global sustainability (Emerson and Hartman, 2006). Yet others appear to confront these issues in a more resolute and mindful way, searching for a new consciousness and conscientiousness to guide science, technology, resource distribution and human relations on a more meaningful path toward a more hopeful future (Laszlo, 2006; Hawken, 2007).

Integralism, the theoretical foundation of Sorokin's later sociological theory, is both an epistemology and ontology, and it includes psychological, sociological and 
social-change perspectives as well. As a system of truth, it describes human capacities as three-dimensional: body, mind, and soul or spirit (grounded in the senses, reason, and faith $^{1}$ ). These three capacities are manifested at the collective level as major types of culture: ideational, sensate and an integrated form termed "idealistic". Sorokin suggests that only an integral culture and personality, which reflects the whole person and the interrelatedness of all, is able to support a more stable and harmonious personal and collective life (Jeffries, 2009; Johnston, 2006; Nichols, 2006, among others).

Throughout the last decades, numerous people began claiming subjective intuitive unitive experiences, within diversity, providing previously unrecognized knowledge about life and reality, a deep sense of inner knowing and of personal/planetary oneness, that all life in the planet is deeply interconnected, and that every "separate" action affects the whole. Many also started drawing from their personal experiences to motivate themselves in their new social behavior and turned their attention "outward", so to speak, actively and vocally. Many who were originally "outwardly" oriented began reporting experiences of subjective experiences of oneness (Harman, 1988).

This awareness, based on reason, intuition and experience, comes about with a shift in attitude, in an orientation of character which determines the relatedness of the person to the world as a whole. Such attitude is a striving towards a mature, and not sentimental, love; towards overcoming human separateness and attempting to honor that universal human longing for union (within diversity) spoken of by the philosophers, mystics, and psychologists of all times (Fromm, 1963). Organic to it is an expansion of consciousness and sense of self incorporating a multidimensionality of life, a strong sense of caring and voluntary responsibility manifesting in lifepreserving behaviors for the best of all.

Such a challenge requires undertaking a parallel personal transformation as part of our individual and collective responsibility for all of life on the planet, to look for deeper resources within ourselves and so to change

\footnotetext{
In our contemporary planetary evolution it is necessary to distinguish the institutionalized spiritual from the general concept of the spiritual so to encompass the whole of human existence with all its transcendent features (Morris, 1964). The intuitive capacities of optimism, inspiration and hope -rather than "faith" -- seem broad enough as to be grounded in "the highest common factor" of the human spirit, and not within religious dogmas (Huxley's Perennial Philosophy (1945). For the emerging transpersonal perspective (Maslow, 1969) and Harman (1988), among numerous others.
}

our internal image of reality, to find a truer, integral (in Sorokin's terms), perspective and sense of meaning.

These insights from the "hidden mind" (Harman, 1984) can be seen as "creative breakthroughs" (or "intuition", "creativity", "inspiration") suggesting the mind's ability to know itself far beyond ordinary experience and the clear value-direction of such overall perspective towards an expanding universalistic view, referred to by insiders as "unity within diversity". The purpose of such experiences which are "beyond" the realm of conscious rationality, referred to by William James as "a noetic ${ }^{2}$ sense of truth", is not to supersede fact, but to supplement it; closely resembling what Morris Berman in The Reenchantment of the World (1981) calls "participatory consciousness" a consciousness of belonging, a merger, or identification with one's surroundings. It bespeaks a psychic wholeness that has long passed from the scene, since the Scientific Revolution and the progressive disenchantment so poignantly observed by Weber as characteristic of the modern epoch. This sense of belonging and of implied responsibility appears to be the essence of what it means to be what is called a "global or planetary citizen", or a "cultural creative" (Laszlo, 2006).

Eventually, this phenomenon was beginning to show the signs of a social movement towards planetary consciousness, in the sense of a moving, through conscious and collective intent, in the direction of some mutually-chosen option. A common denominator in the nature of these incidents of personal transformation, and what constitutes it as a social movement, is that it assumes conscious responsibility for, and intentional stewardship of, our planet home and the life upon it: a conscious intent to best serve the cause of all of life in its fundamental interconnectedness and belonging and an active choice towards love and compassion for all beings, based upon the understanding that our fate is deeply collective. Within a recent historical perspective, this movement can be traced back to the diverse "counterculture/ consciousness movements" from the 1960 's and 1970's, originally manifested in groups with a variety of focuses which, nevertheless, were expressing different aspects of the same sociological gestalt.

Throughout the 1970's it seemed that what once appeared to be two rather unrelated topics of interest, namely, the nature of human consciousness and the transformation of societies, could be more clearly

\footnotetext{
"Noetic" comes from the Greek word nous, which means "intuitive mind" or "inner knowing” (Harman, 1984).
} 
Int. J. Peace and Dev. Stud.

recognized as different drops in a single wave of transformative change, a fundamental radicalization of minds, a "global mind change" seen as necessary for a trans-modern age (Harman, 1988). This convergence, this integration of insights from civil rights, feminism, "New Left", environmentalism and peace, as well as the growing interest in "human potential" and eastern/indigenous cosmologies that explored the subjective experience, suggest the organic interconnectedness of all those aspects of human experience; as a movement it truly transcends commongroup affiliation and behaviors and, in fact, any readily observable activities. It manifests a high degree of change and flow, of diversity, lack of center or single hierarchy, and is truly a grassroots phenomenon. Such fluid, dynamic characteristics present obvious challenges to most sociological, methodological, epistemological, ontological and cognitive foundations, to the extent of rendering it practically "invisible" to politicians, the media, and our discipline as well (Hawken, 2007).

Notwithstanding the importance of theoretical debates on the relationship between altruism and egoism (Simmons, 1991) or whether sociologists may or need to embark on the determination of moral virtues (Bell, 2009) such as "sustainability", and our discipline's general avoidance to study love, altruism, and compassion (Del Pozo Avino, 2006; Oliner, 2006; Weinstein, 2008, among many others), it is obvious that people and peoples urgently need hope, an optimistic vision of a possible sustainable future.

Given the deep-rooted, mostly unconscious, cognitive and affective obstacles to optimism, altruistic love and compassion (Broome, 1991; Williams, 2008), "inner" and "outer" work are obviously deeply interconnected. From the perspective of planetary activism, optimism is an attitude, a commitment, a conscious choice, and not an emotion. It is the ground from which the vision and subsequent actions for a sustainable future can grow.

By no means is the author attempting to imply that these are the main mechanisms that will carry it out, or that it will happen spontaneously, as many of the subjective experiences did.

On the contrary, such complex and difficult transformation requires a committed professional activism, hand-in-hand with the inner work, and it will possibly take decades or even centuries to unfold. As social activist and Buddhist philosopher (Macy and Brown, 1998) suggests, crucial in this is awakening our will act, joining hands to find the ways the world self-heals: of course, we have no assurance that this will happen in time; if it does not, continues Macy, "it will be for lack of political will." ${ }^{3}$

It is not easy and it is far from clear at this point in time how we can carry out the necessary planetary transformation without divisionism, hatred, wars and force. We have been taught by human experiences and by history that these are the main social change mechanisms of humanity. Yet, hopefully, the strategies of the past may not necessarily be those of tomorrow, they seem not to have worked, or at least they are not working anymore (Hayes, 1990; Laszlo, 2006).

Searching for stairways to peace within power asymmetries, in a deeply segregated society as reflected in the microcosm of the academic college, as my culturally diverse students and I were involved in a process of inner and mutual dialogue, discovery and caring, so that we could meet each other as partakers of our common human destiny here and now.

\section{HOLISTIC AND PUBLIC SOCIOLOGY AT UPPER GALILEE ACADEMIC COLLEGES}

As a microcosm of Israeli society, academic colleges in the northern Israeli Galilee reflect Israel's rich multicultural diversity and, very poignantly, the profound human and social "invisible" barriers and divisions between the students. Not surprisingly, these basic power asymmetries (Clements, 1997) between Jews and Arabs, created both by law and by hegemonic discourse, are reproduced in them, and are manifested in practically all informal aspects of academic life, as they are in society at large.

Undoubtedly, these asymmetries are powerful barriers to meaningful, authentic, multi/inter/cross-cultural encounters and communication which are anchored both in daily life experiences as well as in deep (mostly unconscious, this paper dare say) cognitive-affective mechanisms that strongly influence our social construction of reality. No wonder, then, that when in a common academic training process the students are faced with "the other" (as they tend to refer to each other's cultural/ethnic group), they are at a loss of

\footnotetext{
For pertinent critique to Burawoy's implicit association between critique/reflexivity and left politics (Abbott, 2007). Ironically, an integralholistic activism is dismissed both in conventional left politics as nonprogressive, and also in right politics on the grounds of being too radical.
} 
direction, and they mechanically reproduce the prevailing intercultural abyss.

Again and again, in the regular courses, and on the campus at large, one can readily recognize an invisible yet obvious barrier among the various unnamed groups in sitting arrangements in the classrooms and in the library, and in informal gatherings on the campus at large. It is easy to sense the students' uneasiness in shared spaces, and, above all, the mute unexpressed fear in the eyes of these young people, fear tainted by past and present experiences of displacement, occupation, marginality, insecurity, and the ever-looming threat of mutual/total annihilation in public discourse.

In the holistic spirit of planetary consciousness, a workshop format, and an array of classroom interventions and processes were implemented to facilitate empathic cross-cultural communication skills between Arab and Jewish students and the development of a planetary/ unitive consciousness (within diversity) towards cooperative action; simply put, to help them discover each other in their common humanity, their common fears and pains, as well as, of course, their common joys, hopes and visions. From 2002 to the present, twelve formal and four informal workshops were held, each meeting in four-hour sessions over a semester in two Upper Galilee Academic Colleges. Progressively, and in a spontaneous fashion, as budget constraints limited these intimate settings and the need was increasingly evident, the author have started implementing some of the empathy-fostering techniques mentioned below in several of the regular academic courses, as they reflected Israeli society's demographic characteristics and challenges. All in all, 340 students participated in these workshops, and about 300 in different courses (with an average of three or four "circle sittings" each).

The starting point of this project was a three-year ethnographic study which began in 2000 , studying the intricacy of perceptions, experiences, identities and attitudes of Arab and Jewish students at two different colleges. As the findings were, of course, not surprising, reflecting the deep abyss among Jews and Arabs in the country at large, the author was faced with the ethical dilemma: whether to publish the results ("in the name of science and/or academics"), regardless of their further despairing and demoralizing impact, or to assume an involved participant/leadership role towards empowerment, empathy, optimism and hope. From the viewpoint of a mother, an elder, an educator, and a sociologist as well, this was not true dilemma, hence it was necessary to wholeheartedly proceed to implement the latter.

\section{WORKSHOP SETTINGS}

In a relatively isolated classroom on campus -- which supported the creation of a safe space in which students could learn to trust themselves and each other, to explore and express deep responses to the multicultural encounter, as well as to practice empathic and caring relations uncommon in daily life - students met in weekly four hour sessions throughout an entire semester. An average of 26 students participated in each workshop, of which there were generally about one-third Jews, onethird Muslims, and one-third other minorities (Druze and Christian in particular). Men and women were usually equally represented in these groups. The students' diverse backgrounds reflected Israel's rich multicultural characteristics: religious/secular, urban/ village dwellers, modern/traditional lifestyles and gender norms of behavior. All of these were manifested in different dress codes and social norms of contact and interaction in general, particularly between men and women of diverse backgrounds. Such an intimate, ongoing, gathering among them was in itself a novel and extraordinary experience in the larger social context. Students sat in circles or in smaller intercultural groups or dyads, following empathic listening guidelines, with allotted times for each person to express him/herself, and each respecting the other and also experiencing silence while listening. Sharing was carried out in first person, excluding all conventional political or generalized/stereotypical discourse from the process (after the first workshop, and Arab and a Jewish student workshop graduates were recruited as assistants in the subsequent ones).

\section{WORKSHOP "SETTING" OR INTENTION}

Each meeting opened with an intentional demarcation of the meeting as a "sacred circle" (not in any religious sense but in the Native American spirit which sees as sacred all that supports and sustains life). This was accompanied by a statement of intention of our work together, that is: our contribution to more harmonious intercultural relations and the healing of the world. A formal verbal closing of the sacred circle ended each 
Int. J. Peace and Dev. Stud.

session. Interestingly, students were very receptive to such structure, though it is quite foreign to their daily life. The main aim of these processes was to encourage discovery of self and other, and to search for and support factors conducive to the experience, or intuition, of unity within diversity. The holistic framework was manifested in the integration of learning the principles of planetary consciousness, promoting and providing space for deep emotional work, facilitating guided imagery exercises towards future hopes and visions, as well as diverse physical activities (stretching, breathing and moving exercises, role playing and on several occasions traveling off campus together ). The author was actively involved in all of this. The leader has a dual role here- being alert to the group as a whole as well as actively participating in ongoing process and in exercises.

The workshop practices drew from an extensive body of strategies within a holistic-systemic sociological framework as formulated in the principles of planetary consciousness. In particular, but not exclusively, this paper drew from the theoretical and experiential work of planetary activists Doug Boyd and Joanna Macy. Boyd (1985), drawing on decades of innovative research as founding Director of the Cross-cultural Studies Program, stresses the vital role of empathic communication for intercultural understanding and cooperation, allowing participants to transcend fear and the adversary perspective. Macy's experiential process, The Work that Reconnects, allows people to share the fear and the pain for our world's condition in a safe environment: emotions deeply denied and disavowed in mainstream society, the forceful repression of which is the cause of what, to her, is the greatest danger, that is, the deadening of the mind and heart and its resulting inhibition of the will to act and of the belief in the impact of our actions at the social realm. Together with empathic inducing interactions, workshops drew from Macy's sequential process in her Work that Reconnects (Macy and Brown, 1998), that is: affirmation: coming from gratitude; despair work: owning and honoring our pain for the world; the shift: seeing with new eyes; deep time: reconnecting with past and future generations, and going forth: learning we bring back into our lives and our communities. Yet, as the main aim of the meetings was to identify and encourage anything that promotes unity, a sense of community and shared humanity, there was also ample room for spontaneous, unplanned and unstructured activities idiosyncratic to each group. People shared family histories and pictures in their groups, shared typical foods with each other, brought their favorite music and listened together, played music, taught each other childhood songs, drew their fears and visions, and even spontaneously hosted the entire group at their family homes, to name but a few.

Each and every time, deeply moved, one could observe the students' transformation from the original distancing, fear and mutual distrust to a joyful exploration of their mutual curiosity, sharing pains and fears for the world and recognizing deep-rooted stereotypical constructions of reality; invariably, these evolved, rising like the phoenix into a deep sense of caring, an intuitive shift of perception about self and other as an interrelated unity. The students' quotes presented below represent "typical" voices in the diverse settings.

\section{CONTACT, COMMUNICATION, COMPASSION}

Although these students often sat together in class, and many lived in geographical proximity, personal contacts with "the other side" (as commonly referred to) were minimal. Each and every time, the very opportunity to sit together intentionally, by voluntary participation in the workshops and their processes, and to get to know each other, was a very meaningful experience, with a remarkable element of novelty, welcomed with anticipation as the following typical voices express:

"... the lack of communication between Arabs and Jews in the state of Israel worries me so much.... it creates a lot of fear on each side, fear, uncertainty, stress, misunderstanding, a different world view, more hate... here I want to meet new friends, especially Jews, because the only place I can meet Jews is on campus ... As a Muslim person living in Israel I never believed I would sit with Jews as brothers, so close!... most important... [is] to create an environment of quiet, ease, and to overcome the fear that is buried in each one of us."

"...here we have the opportunity to learn about people behind this or that label, and stopped looking at "them"... it gives us a sort of "stage" which allows us an opportunity to see the people themselves, their thoughts, their way of life, their perceptions about our daily reality. We are enclosed in what's portrayed in the media, in books, what we're being told... here we can talk about the painful stuff for both sides... so we can reach an initial understanding and the rest...then....will have less impact..." (Jewish, secular, woman) 
"I belong to the Druze community and see myself as a kind of bridge, a uniting factor between both peoples. On the one side, I'm Arab. Arabic is my native tongue, and, on the other side, I belong to a group whose sons do serve the country in the military, I even have four brothers in the army now... Here we can meet and talk."

After the initial encounters, typified by mutual fears and distancing, the process of trust within the carefully structured safe space progressively deepened and group members began to share deeper emotions face-to-face, often grounded in widespread stereotypes about "the other" Expressions of fear began to emerge from all students, referring particularly to the beginning stages of the process:

"I came with not a few fears and concerns that it would be hard for me to participate in this circle and become an organic part of the people in it. I come from a Jewish religious background and before sitting here my ideas were pretty harsh... and I did not believe in living together, or that such friendships could exist among Jews and Arabs...but it soon became clear to me that such a thing does indeed exist, living together, two different peoples. And not only can we live together fully, but there are also many common things to both peoples of which I was unaware before participating in this workshop. At times I even forgot that I was sitting with Arabs, talking with them, but related to them as to any other person I am in contact with. I wish that the whole world would arrive at the same point of mutual understanding and caring so that we could overcome the strife within us."

"For me, as a person who lives in a difficult country and period, of confrontations among Arabs and Jews, we live in times full of fear, hatred, indifference, etc... here I'm managing to overcome all this, and I understood that now is the time for healing, bring back the trust, the possibility to listen, to observe myself... and all this through dialogue, dialogue between Arabs and Jews, with human respect as our common ground... to stop seeing the Jews as bad, exploiters... and the Jews also stop thinking about the Arabs as criminals, terrorists, etc... just to be silent and listen, attentively... This unity can bring about peace... and if not peace, at least less fear and frustration...." (Muslim, village-dwelling, woman)

"In fact, I've started to get some answers, for myself... how to overcome the fear of a bomb attack, sitting at a coffee house in Tel Aviv, how to ride a bus, etc.... it's been very helpful to understand the other side, and to understand myself as to why l've felt that fear. Now I know how to deal with it. And now I want to help them face their fears, and I am telling their side to my family and to my friends... to spread the word for more understanding and tolerance" (Jewish, urban, secular, woman).

"It takes courage and strength to talk and create a relationship with them, with the "other side", different from me... and listen and give it the chance to express itself, and to myself as well... to trust myself and express myself with no fear and no lies but just simply tell the truth... and search for new ways for a better standard of living for all... and not to think only of myself." (Druze, secular, man)

Indeed, such expressions seemed to consistently pave the way for intuitive insights or perceptions of commonalities and caring.

Expressions of anger were also voiced at the "national security" situation, tentatively at first, more freely later on, somewhat more directly by Jewish students (anger at Arabs in general, not really distinguishing at first between the Israeli-Palestine conflict and their fellow classmates).

"For me, our first contact was very complex... indeed, I wanted to participate, but was not sure it was the right thing to do... I was full of anxieties and no little anger towards the Arabs [her emphasis]... A friend of mine was killed in a terrorist bomb attack when visiting Jerusalem... I was afraid of them, but I was also angry... yet, it did not feel right... I see myself as an open, liberal, person, so I've opened up to this process, and suddenly, or really step by step, I've realized that my Arab classmates aren't responsible for those acts, that also they are sometimes pushed into a corner ... and that they are also afraid and angry... the block was removed from deep within and l've found myself and I've found then... all through dialogue and listening... tools for life..."

Arab-Jewish systemic power asymmetries were, of course, reflected in the encounters, probably all through these processes: ${ }^{4}$ Arab students tended to be less verbal (most of them were not quite fluent in Hebrew and have

\footnotetext{
${ }^{4}$ For an excellent discussion on the impact of the minority status of ArabsPalestinians in Israel (with the resulting unequal distribution of resources) on the features of discourse within the encounter between the groups in conflict (Maoz, 2001).
} 
Int. J. Peace and Dev. Stud.

less-assertive communication styles than young native Jews), more hesitant, less direct in their expression of negative emotions towards "the other"5; yet, slowly they did start to verbalize some of their minority experiences, as these quite typical voices reflect:

"It's hard for me to talk with Jews...it's not my language... so I think to myself -- why bother to speak, in a language that is not my own, with people I fear will not understand me nor will I understand them?! I now want to know the other culture, in the midst of which I live my whole life, and give them and myself the chance to know the truth about each other."

"I was curious about the Jewish majority and felt the need to know them, how do they think... how do they feel? I never felt I could until now..."

"I feel that I did not convince the other side, "the Jews", of our outlooks and our feelings about coexisting here... but at least I've talked to them and I felt that they've listened... it's a start for me, a first, a big one..."

It is obviously impossible to reach solutions for such deep and complex challenges within three, four or fourteen encounters, but we can bring them into consciousness together, as one more brick towards building the stairways to peace. It is possible to have a 'sense' of the other culture and of the people as people, to know each other, to listen and 'get' the perspective of 'the other', through mutual respect and empathy - to accept, even with no rational understanding, that there is another point of view.

"I knew I had to be part of this process because, at a personal level, I've had some inner block towards Arabs... and it bothered me a lot... in this process there were ups and downs...but I've learned to understand the pain of the minority, and identify with it. To understand the fear, suspicion and the sense of alienation from the experience of an Arab woman student who comes to college... and from there arouse in me the will to help them, to recognize them as people with unique personalities, each one with a life story... with no stigma or stereotypes that were in me towards them..." (Jewish woman, Moroccan ancestry)

\footnotetext{
5 In the beginning processes, most students were very uncomfortable naming the "other" group as "Jews" or "Arabs", and when used those words were embarrassed and apologizing. Eventually this became an "inside joke".
}

As the process of empathic communication deepened, a sense of connection, from the heart, and a perceptual shift towards compassion began to emerge, as the following quotes suggest:

"I never thought that Jews also suffer from the antagonism and hostilities among our peoples, that they are also afraid, insecure, and in no little despair ...I met them as friends, as intimates even, and learned that we share the same pains, the same dreams, and the same hopes. My bitterness towards them started transforming into a surprising understanding and even some forgiveness. This inner change took me totally by surprise, and today it feels like part of me. I never thought I would open up and share such intimate experiences, let alone with friends of the "other's group", called "enemies" in the outer larger circle!! On the contrary, at times I have now even felt more comfortable sharing some things with the Jewish fellows than with the Arab ones. I've started talking about "us" and "them" and then became confused-is it me? Is it us?" (Muslim, religious, woman).

"At the beginning I felt very uncomfortable in the circle, as a Jew with a right-wing ideology. I did not connect with the exercises and did not really understand where they lead to. But as it unfolded I really connected with the people. Here l've learned and experienced that the main reason for suspicion, and for stereotypes which lead to hatred, is simply that we don't know each other, and therefore we don't open up and allow ourselves the privilege to know one another as people. I believe that in the establishment of a dialogue like this, or even in a joint work context, we could break down the walls that divide us and treat each other as fellow humans, independent of identity. In fact, we are all the children of Abraham and just as in all good families there are fights among siblings, we need to overcome our differences."

And in the process of beginning to see others, most students begun to discover themselves, as was very common to hear among many:

"... funny... when I found 'them' I found myself!!"

The clear connection between empathic communication; self-discovery/discovery and an emerging unitive consciousness, within the cultural diversity, is exemplified in the following example, similar also to expressions by Jewish students towards the Arab ones and between all diverse groups: 
"Personally, I found in me a side unknown to me... the one which can listen and understand the "Jews" ... sorry! [for calling them so] But this is really what happened to me, because in the past I found it very hard to understand and listen to the "Jews"... and, in truth, now I've met not only the other but myself.... I've learned about the Jews, started to understand them..., also learned about myself a lot, l've opened up to myself and to classmates, from all sectors...And I love very much the connection between all of us!"

In a rather organic, synergistic, fashion, the experience of seeing the other people and cultures from their perspective, tended to evolve into a sense of oneness, of unity, within diversity, moving closer to some experience of compassion, described by Macy (2012) as: "... to search for the deepest human experiences which make us shift from conventional perceptions to the question of "How can I help to alleviate the pain and suffering of others?" It rests on a deep inner knowing that allows meeting a fellow human being with similar experiences, with a deep sense of caring, as this Muslim religious woman student manifests:

"... I was shocked when I saw this Jewish classmate crying, telling us about her grandmother's deep distress since having to leave behind her home in Lebanon, with Israel's independence ... her family dispersed all around the world... and for a moment, it was weird, intense... I heard...almost physically!!... my own grandma in the background, crying the same tears, the same cries... And I was moved to support her, to listen to her, attentively, and to tell her story to my people... they have also suffered dislocation, dispersion, uncertainties because of their religious/ ethnic background... My telling others is my contribution to a better understanding between us all."

A similar Jewish religious woman's voice resonates with this:

"... now I realized that what I felt in my heart they feel it too... that just like we suffer, they do too; that they are just people, like you and me... and everything that happens in the country doesn't hurt only me, but it hurts them as well. Suddenly I saw everything in a different light. There were days when I would arrive at our college and would meet any of the new friends ... and then I felt a certain happiness, a spark that" "Yeah!! I've accomplished something!" Indeed, we did get close. I started to feel that we are part of each other, that there is no more "them". I became a "full time member" and at recess time I would sit with Arab student friends, and opened up deep conversations with them which led me to know them at a much deeper level."

" As a mother, I fear for my children, and the Jewish children, and the Muslim, and all... just born into this split, dangerous society ... we must join hands for all the children, passing on some wisdom about our common humanity and destiny... getting to know the 'other side', teaching them to strive, together, for peace. As a mother, I would like to see my children grow up into a different reality... The change cannot be done by politicians, it must be started by the common people, people like us. I want to live in peace; I want my children to grow in peace. Therefore, here I am." (Druze, woman, student)

Indeed, deep emotions were expressed, even those tabooed in the hegemonic discourse, such as this painful lament of a young Jewish man, who had served in a combat unit in the army:

"I try to understand the cold heart of Israeli society and ask myself- where?! Where were our parents and grandparents mistaken, after being -- in the past, in Europe, or anywhere else on the globe-- a minority and discriminated against?! , and ...where from came this deadening of the heart when they became the majority... when?!... from being persecuted and dominated they have reversed the roles... physically and emotionally as well...?!"

Also, a young religious Muslim woman who identified herself as "Palestinian with Israeli passport" (rejecting Israeli identity) expressed a similar inner "revelation" of sorts:

"I and most my Arab friends were convinced, with critical eyes, that Jews had no rules, no norms to comply with, and did whatever they feel like. But l've found that they are much like me. That does get us really close. I've started getting close to Jewish women who today are my friends. I've never thought or believed that that I would have close Jewish friends and confidants!... Even soldiers, whose mere sight would inspire automatic almost hatred in me... now, I look at them and see young men who by law have to serve in the army... and I do wonder whether they are fellow students, and how do they really feel and think. Just like many of the Jewish 
men sitting here, so other soldiers may be just like them... I even give rides to soldiers who seem on their way to College - some of them do not accept it but some do, and then we start talking, and you see that he's a good person and he is bound by law to serve in the army... and maybe just like I have helped him, he'll help one or two others... my mom has difficulties accepting this and my friendships with Jews and I explain to her the process I went through and what I've learned about us all being in this together... I explain to her the feelings of oneness when we sit in a circle together, the deep respect, trusting disclosure, our overcoming stereotypes... Funny ...the fundamentalists on every side are very much alike, and the peace people are also very alike in all cultures. It's the person, not the group, that matters."

By no means does this section succeed in conveying the wide array of shared activities, events, insights, or powerful reverse role-playing enactments which brought us all to tears and laughter, a sense of comradeship beyond substantial disagreements, love and hope ${ }^{6}$. We were guests in students' homes, in Arab villages (and in their mosques), in Jewish homes of diverse backgrounds, in kibbutzim, in young students' residences and dorms, each time breaking down a little more of the allegedly "invisible" barrier that few in society at large dare to cross. Both sides participated in these events with hesitancy at first, yet with a sense of expansion, of a kind of optimistic revelation, increasingly searching for ways to meet and help each other and to continue this process outside of school as well.

For example, on several occasions, we were guests, as a group, at Ramadan family dinners in various Arab villages. This in itself was a novelty (almost a taboo transgression) for many Jewish students, requiring overcoming fears and deep-seated stereotypes, and it consistently led to comradeship and to open feelings of joy. On these occasions, Arab students became much more verbal and spontaneous, taking active roles in explaining their culture, offering translation services,

\footnotetext{
There have been, of course, many dilemmas and challenges as well, which accentuated the separate, if not adversarial identities. Yet in the empathic dialogic process they evolved into a common agreement that these are to be expected, not resolvable within the given time-context limitations, and that the first step was just to be able to meet as people, creating thus a common ground for future negotiations on the deep substantial issues that divide both groups. Groups that focus on the Israeli-Palestinian conflict have shown a tendency to accentuate the abyss between both groups.
}

feeling grateful for the Jews' interest in, and respect for, their culture, such as " the respect that the Jewish women in our group gave us by wearing the head cover...", "... their listening to the sheik's religious explanations so attentively", "their walking around in the village with us, with no fear and such curiosity and respect".

For most of the Jews, the visits to the mosques were "extraordinary", "a true experience":

"Personally, for me, it was moving moment ... especially after the Sheik's talk ... when we were outside the mosque ... and the muezzin started praying... I grew up a few meters from an Arab village and I can remember the muezzin's calls from the time I can remember myself....personally, it always sounded nice, but that day it sounded even nicer; because after the talk with the sheik I also understood part of the prayers...

I stood and listened and thought about the essence of the prayers; the way the sheikh explained to us. And it was very significant for me."

"...after the [Arab] students' explanations... I even managed to find some similarities between the mosque and the Jewish synagogue...in fact they both fulfill the same function!!" (Note that to an outside observer this would be obvious and self- evident!)

"... a real meeting between the two groups, Jews and Arab in a Holy place, as the Sheik said, the house of God. And their goal is peace. For me these are truly unforgettable moments."

As Broome (1991) suggests, the expression of discomfort, stress and anxieties about dissimilarities did indeed result in new meanings and the developments of stronger ties with an open approach. Students were not asked to set aside stereotypes, but to recognize them and work with them. From that process of mutual and self-discovery, through empathy and sharing deep emotions and beliefs, unitive insights emerged among most participants in all contexts. As these deepened, one could see the growing concern with the suffering of others, accompanied by the urge to help (Sznaider, 1998) that manifested in an optimistic vision, a glimpse of hope for living together in peace, united by the common love for each other and for this land. Most students were, in 
fact, spontaneously moved to act, to "spread the word" on empathy and unity-within-diversity to their communities, helping each other in school matters, intending to visit each other after school, writing articles to the college newspapers, sharing their experiences on local radio stations, and even just sitting together as friends on campus, beyond the "not-always-visible" wall. Tentatively at first, yet consistently, a common vision of possible peace between all of us did emerge.

Of course, all the above can be considered, in many ways, just "a drop in the ocean" towards sustainable peace and justice in this land. Yet its fundamental significance lies in the recognition of a deep inner truth, common to all, a sense of optimism and hope, reflected in a shift in the perception of reality that allows previously untapped capacities, possibilities and strategies to emerge.

\section{DISCUSSION}

\section{Will we choose fear or will we choose love?}

This paper describes cross-cultural encounters, within principles of empathic communication, between Jewish and Arab students in two academic colleges in the Northern Galilee, Israel. Students involved in these processes evolved, even if only for a few fleeting moments, from a marked initial segregation, and even latent hostility, into a sense of mutuality, of oneness (within diversity), a social sharing that does not really distinguish between "mine" and "yours", or often even between "me" and "you". This came about in a creativeintuitive process of deep self-and-other discovery that transcended deep-rooted affective and cognitive foundations of constructions of reality as adversaries, and even enemies. A process of empowerment is involved, based upon relationships, on the recognition of a common humanity, reflected in our efforts to help people move towards an awareness of human misery and an awareness of how our own actions affect and even maintain such misery and injustices and oppression; most importantly, it leads to a renewed sense of hope and to an optimistic vision of sustainable peace in Israel which aspires toward social responsibility and cooperation.

Grounded in an integral-planetary consciousness perspective, this experience suggests that empathy, caring, loving and compassion taken together as a synergistic gestalt of pro-social behavior ${ }^{7}$ can indeed be trained. More than that, such training is urgently needed for life as we know it, in this country, and on our entire planet, in order to survive and thrive.

Yet this requires a profound paradigm shift in our discipline, so as to embrace the subjective experience together with our structural analyses of the planetary circumstances, the promotion of necessary institutional change and a committed activism towards a sustainable society. Such framework simultaneously embraces the four dimensions suggested in Burawoy's holistic sociology: it is based upon a wealth of multi-disciplinary research $^{8}$, it is radical, it aims at character formation and social reconstruction, and finally, it is involved with urgent planetary issues while oriented towards the public at large. As a transformational process, it necessarily includes us, the "experts", as organic part of the "public audience" inviting us to understand and transform ourselves as we intend to understand and transform society.

This perspective resonates deeply as well with the deep eco-feminist spirit and its emphasis on wholeness as a creative rebalancing of male and female energies, both present and latent in women and men alike; between aggressiveness and nurturing, competition and cooperation, rationality and intuition. It is about the transition from a "dominator" model of society to a "partnership" model that organizes human relations so that the "soft" or "feminine" values of caring, compassion, and nonviolence do not have to be devalued (Eisler, 1988; Spretnack, 1993).

"For ourselves, and for the sake of our children and their children, let us use our human thrust for creation rather than destruction. Let us teach our sons and daughters that ... we have the knowledge and the capacity to survive (and to thrive); that we need not blindly follow our bloodstained path to planetary death...

\footnotetext{
${ }^{7}$ Though it is not the aim of this paper to engage in a literate, rational, dualistic analysis of each of these terms, I shall emphasize that all of them are here perceived as verbs, rather than nouns, as they exist in process and are about relationship (Fromm, 1956; Macy and Brown, 1988; and the whole body of transpersonal approaches). I have also limited the use of the term "altruism" as it requires an analysis of whether semantically it is grounded in a dualistic perspective, and, if seen as another aspect of loving, it includes self-love as well. Such discussion, although very relevant, is regrettably outside the scope of this paper.

8 As in the emerging holistic-systemic "science of consciousness", or so-called "new sciences", that embraces the whole range of human experience, such as social sciences, humanities, new physics, biology, brain research, ancient cosmologies, and others.
} 
Let us regain our lost sense of wonder and reverence for the miracles of life and love..." (Eisler, 1988, pp. 123124).

\section{ACKNOWLEDGEMENT}

Thanks to Kinneret College at the Jordan Valley for partly supporting this research by a grant.

\section{REFERENCES}

Abbott A (2007). For humanistic sociology. In D. Clawson, R. Zussman, J. Misra, N.Gerstel \& R. Stokes (Eds.), Public sociology: Fifteen eminent sociologists debate politics and the profession in the twentyfirst century. Berkeley, CA: University of California Press, pp. 195206.

Bell W (2009). Public sociology and the future: The possible, the probable, and the preferable. In V. Jeffries (Ed.), Handbook of Public Sociology. Lanham, MD: Rowan \& Littlefield, pp. 89-106.

Berman M (1981). The reenchantment of the world. Ithaca, NY: Cornell University Press.

Boyd D (1985). Communications: The purpose and the process. CrossCult. Stud. Program Rep. 16:7.

Broome BJ (1991). Building shared meanings: Implications of a relational approach to empathy for teaching intercultural communication. Commun. Educ. 40:235-249.

Clements KP (1997). Peace building and conflict transformation. University of Queensland, Australia: Australian Centre for Peace and Conflict Studies Publications.

Del Pozo AE (2006). Sorokin and altruism: An inspiration to collective action studies. In E. Del Pozo Avino (Ed.), Integralism, altruism and reconstruction: Essays in honor of Pitirim A. Sorokin. Valencia, Spain: Publicacions de la Universitat de Valencia. pp. 123-144.

Dudouet V (2005). Overview of the field of conflict resolution in the context of asymmetric conflicts. Adapted from Peacemaking and non violent resistance with special reference to the case of Israel/Palestine, PhD thesis, Bradford University.

Eisler RT (1988). The chalice and the blade: Our history, our future. San Francisco, CA: Harper \& Row.

Emerson MO, Hartman D (2006). The Rise of Religious Fundamentalism. Annu. Rev. Sociol. 32:127-144

Fromm E (1963). The art of loving. New York, NY: Bantam.

Gubkin SS (1995). A movement towards the emergence of a planetary consciousness: The case of the San Francisco Bay area. Ph.D. Thesis. Berkeley, CA: University of California.

Harman W (1988). Global mind change: The promise of the last years of the twentieth century. San Francisco, CA: Berrett-Koehler.

Harman W, Rheingold H (1984). Higher creativity: Liberating the unconscious for breakthrough insights. New York, NY: Jeremy P. Tarcher.

Hawken P (2007). Blessed unrest: How the largest movement in the world came into being, and why no one saw it coming. New York, NY: Viking.

Hayes R (1990). Activism. You make the difference. In S. Head \& R. Heinzman. San Francisco: Sierra Club Books/ Lessons of the rainforest, pp. 219-233.
Huxley A (1945). The perennial philosophy. New York, NY: Harper \& Row.

Jeffries $V$ (1999). The integral paradigm: The truth of faith and the social sciences. Am. Sociol. 30(4):36-55.

Jeffries V (2009). Redefining the nature and future of sociology: Towards a holistic sociology. In V. Jeffries (Ed.), Handbook of public sociology. Lanham, MD: Rowan \& Littlefield, pp. 1-25.

Johnston BV (1999). Pitirim A. Sorokin on order, change and the reconstruction of society: An integral perspective. Comp. Civilizations Rev. 41:25-41.

Johnston BV (2006). Sorokin on social order, change, and the reconstruction of society: An integral foundation. In E. Del Pozo Avino (Ed.), Integralism, altruism and reconstruction: Essays in honor of Pitirim A. Sorokin. Valencia, Spain: Publicacions de la Universitat de Valencia, pp. 145-156.

Lasch C (1984). The Minimal Self. Psychic Survival in troubled times. New York, London: W.W. Norton \& Company.

Laszlo E (2006). The chaos point: The world at the crossroads. Charlottesville, VA: Hampton Roads.

Macy J (2012). Joanna Macy and her work. http://www.joannamacy.net/engaged-buddhism.html.

Macy J, Young Brown M (1998). Coming back to life: Practices to reconnect our lives, our world. Gabriola Island, Canada: New Society Publishers.

Maoz I (2001). Participation, control, and dominance in communication between groups in conflict: Analysis of dialogues between Jews and Palestinians in Israel. Soc. Just. Res. 14(2):189- 208.

Maslow A (1969). The farther reaches of human nature. J. Transpers. Psychol. 1(1):1-9.

Morris R (1964). The concept of the spiritual and the dilemmas of sociology. Sociol. Relig. 25(3):167-173.

Nichols LT (2006). The diversity of Sorokin's Integralism: Eastern, Western, Christian and non-Christian variants. In E. Del Pozo Avino (Ed.), Integralism, altruism and reconstruction: Essays in honor of Pitirim A. Sorokin. Valencia, Spain: Publicacions de la Universitat de Valencia, pp. 59-69.

Oliner S (2006). Sorokin's major contributions to world sociology. In E. Del Pozo Avino (Ed.), Integralism, altruism and reconstruction: Essays in honor of Pitirim A. Sorokin. Valencia, Spain: Publicacions de la Universitat de Valencia, pp. 13-30.

Simmons RG (1991). Presidential address on altruism and sociology. Sociol. Q. 32(1):1-22.

Smooha S (2009). The model of ethnic democracy: Response to Danel. J. Israeli Hist. 28(1):55-62.

Spretnak C (1993). Critical and constructive contributions of ecofeminism. In M.E. Tucker \& J.A. Grim (Eds.), Worldviews and ecology: Religion, philosophy and the environment. Lewisburg, PA: Bucknell University Press, pp. 181-189.

Sznaider N (1998). The sociology of compassion: A study in the sociology of morals. Cult. Values 2(1):117-139.

Williams CR (2008). Compassion, suffering and the self: A moral psychology of social justice. Curr. Sociol. 56(1):5-24.

Weinstein J (2008). Giving altruism its due: A possible world or possibly no world at all. J. Appl. Soc. Sci. 2(2):39-53. 